\title{
Voltammetric Determination of Epinephrine in Pharmaceutical Sample with a Tyrosinase Nanobiosensor
}

\author{
Şenol Alpat, ${ }^{1}$ Kazım Özdemir, ${ }^{2}$ and Sibel Kılınç Alpat ${ }^{1}$ \\ ${ }^{1}$ Division of Chemistry Education, Buca Faculty of Education, Dokuz Eylül University, Buca, 35150 İzmir, Turkey \\ ${ }^{2}$ Department of Biotechnology, Institute of Natural Science, Dokuz Eylül University, Buca, 35390 Izmir, Turkey \\ Correspondence should be addressed to Şenol Alpat; senol.alpat@deu.edu.tr
}

Received 20 April 2016; Revised 11 July 2016; Accepted 13 July 2016

Academic Editor: Junhang Dong

Copyright ( 2016 Şenol Alpat et al. This is an open access article distributed under the Creative Commons Attribution License, which permits unrestricted use, distribution, and reproduction in any medium, provided the original work is properly cited.

\begin{abstract}
A novel carbon paste electrode modified with a multiwalled carbon nanotube (MWCNT), tyrosinase, and Nafion membrane (CP/MWCNT/Tyr/Nafion) was developed for voltammetric determination of epinephrine (EP). The CP/MWCNT/Tyr/Nafion biosensor exhibited linear dynamic range from $5.0 \times 10^{-6} \mathrm{M}$ to $5.0 \times 10^{-4} \mathrm{M} \mathrm{EP}$ concentration with a good correlation coefficient $\left(R^{2}=0.9985\right)$. The detection limit of the biosensor was calculated as $3.0 \times 10^{-7} \mathrm{MEP}$ from the signal-to-noise ratio $(\mathrm{S} / \mathrm{N}=3)$. Reproducibility of the biosensor was also calculated from relative standard deviation as $3.8 \%(n=5)$. Ascorbic acid (AA) and uric acid (UA) did not interfere in the quantification of epinephrine. The developed biosensor was also successfully applied for the determination of epinephrine in pharmaceutical sample. The CP/MWCNT/Tyr/Nafion biosensor has good sensitivity, selectivity, stability, easy preparation procedure, and short analysis time and can be used for the determination of EP in pharmacological samples.
\end{abstract}

\section{Introduction}

Epinephrine (EP), which is released by the adrenal glands, is an important member of the catecholamine family and it acts as a neurotransmitter and hormone in the mammalian central nervous system $[1,2]$. EP regulates the blood pressure, immune system, heart rate, lipolysis, and glycogen metabolism and its level indicates the presence of some diseases [3-5]. While low levels of EP are observed in Parkinson disease and orthostatic hypotension, slightly high levels of EP are observed in stress and thyroid hormone deficiency [3-5]. Whereas the epinephrine plasma level was measured as $3.0 \pm 3.0 \mathrm{ng} / 100 \mathrm{~mL}$ (mean $\pm \mathrm{SD}$ ) with the regular subjects, it was measured as $4.4 \pm 3.5 \mathrm{ng} / 100 \mathrm{~mL}$ (mean $\pm \mathrm{SD}$ ) with the hyperthyroidism and $4.7 \pm 3.5 \mathrm{ng} / 100 \mathrm{~mL}$ (mean $\pm \mathrm{SD}$ ) with the hypothyroid subject groups [6]. EP can also be used as an emergency agent because it provides oxygen and glucose to the brain and muscles [3-5]. Great efforts have been made to improve analytical methods for determining the EP concentration in various samples due to its importance for nerve physiology, pharmacology, and the life sciences. Various determination methods including spectrophotometry $[7,8]$, liquid chromatography $[9,10]$, flow injection analysis [11-13], capillary electrophoresis [1416], and fluorimetry [17-19] have been used for this aim. Estimation limits of the methods harnessed in studies aiming to determine the EP were found to be $4.4 \times 10^{-6}$ and $0.26 \times$ $10^{-6} \mathrm{M}$ for spectrophotometric methods [8,9], $1.04 \times 10^{-8}$ and $4.0 \times 10^{-8} \mathrm{M}$ for liquid chromatography $[9,10], 2.8 \times 10^{-8}$, $3.0 \times 10^{-9}$, and $1.09 \times 10^{-6} \mathrm{M}$ for flow injection analyses [1113], $9.6 \times 10^{-7}, 0.6 \times 10^{-7}$, and $9.3 \times 10^{-9} \mathrm{M}$ for capillary electrophorese [14-16], and $2.73 \times 10^{-7}, 9.3 \times 10^{-9}$, and $1.5 \times$ $10^{-8} \mathrm{M}$ for fluorometric methods [17-19]. When limits of the EP estimation methods are considered, it was observed that limit value varies in the range of $10^{-6}$ and $10^{-9} \mathrm{M}$ on average. However, since these methods are time-consuming and expensive processes which require derivation operations, they exhibit some disadvantages [3, 20, 21]. Electrochemical methods are commonly preferred alternative methods because of their convenient, low-cost, and short analysis period [21, 22]. Numerous electrochemical methods have 


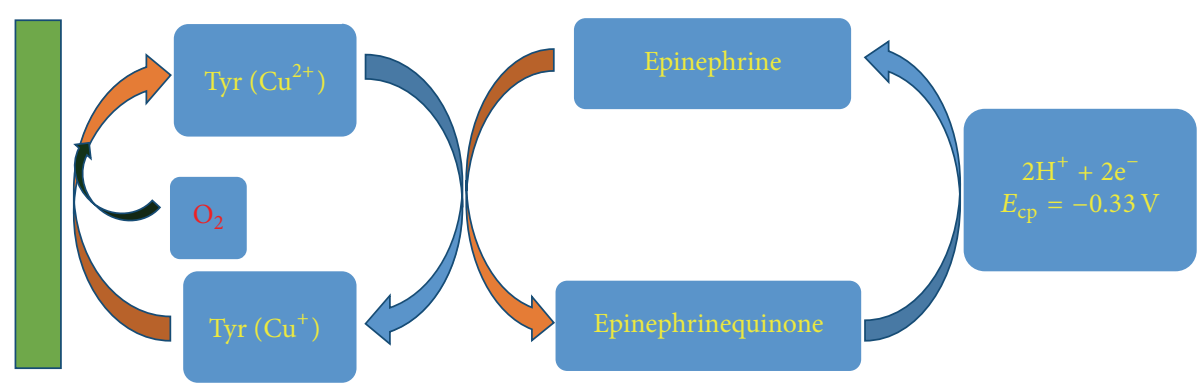

SCHEME 1: CP/MWCNT/Tyr/Nafion biosensor mechanism for EP determination.

been proposed for the determination of EP. Various electrode types such as the pyrolytic graphite electrode [5, 23, 24], carbon paste electrode [4, 25-30], composite electrode [21], glassy carbon electrode [1-3, 20, 31-34], gold electrode [22], and $\mathrm{Pt}$ electrode [35] have been modified and employed for the electrochemical analysis of EP. It was observed that limit of electrochemical methods used to estimate the EP varies within the range of $10^{-6}$ and $10^{-9} \mathrm{M}$ and this yields comparable advantage with respect to other methods [15, 20, 22-31, 34].

Carbon nanotubes (CNTs) have gained increasing attention as electrode modifiers because of their unique structure and physical properties [21, 36, 37]. They have enhanced electronic properties and offer rapid kinetics for the electrochemical process. With regard to sensitivity, detection limit, and electron transfer kinetics CNT modified electrodes have some advantages over traditional carbon electrodes [31]. CNTs have been used for biosensor preparation and they have been successfully applied for the determination of biological compounds [2, 21, 36-39]. Biosensor selectivity for biological compounds can be improved by using CNTs together with an enzyme for modification process of the biosensor.

In this study, tyrosinase (Tyr) was used for the preparation of the biosensor. Tyrosinase and catecholoxidase are from type 3 copper protein group. Whereas tyrosinase mediates the hydroxylation of monophenols to orthodiphenols, it also allows its subsequent oxidation to orthoquinones (monophenols activity). Tyrosinase transforms monophenols along two iterative steps: whereas the first one includes hydroxylation of monophenol into its relevant o-diphenol (hydroxylase process), the second includes oxidization to the relevant o-quinone in which the enzyme goes through oxidization process from molecular oxygen to its original form (the catecholase process). All these proteins consist of almost the same area with binuclear copper active, where its $\mathrm{Cu}^{\mathrm{I}}-\mathrm{Cu}^{\mathrm{I}}$ deoxy form binds $\mathrm{O}_{2}$ reversibly. This results in binuclear $\mathrm{Cu}^{\mathrm{II}}$ unit bound $\mathrm{O}_{2}$ in the lateral bridge form $\left(\mu-\eta^{2}: \eta^{2}\right)$ [40-43].

The possible mechanism of the developed biosensor was given in Scheme 1 [41, 43].

A new biosensor was developed by modifying a carbon paste electrode using the catalytic effect of tyrosinase and the unique properties of CNTs for the determination of EP and the electrode surface was also coated with Nafion membrane to prevent the interference effects of ascorbic acid (AA) and uric acid (UA) on the biosensor response.

\section{Experimental}

\subsection{Materials and Methods}

2.1.1. Chemicals. Graphite powder (Aldrich) (1-2 microns, synthetic), mineral oil (Sigma-Aldrich), Nafion (solution 5\%) (Fluka Chemika), epinephrine hydrochloride $\left(\mathrm{C}_{9} \mathrm{H}_{13} \mathrm{NO}_{3} \cdot \mathrm{HCl}\right)($ Sigma), MWCNT (6-9 $\mathrm{nm} \times 5 \mu \mathrm{m} 95 \%)$ (Sigma), tyrosinase (tyrosinase from mushroom) (Sigma) (3130.87 UI/mg), $\mathrm{KH}_{2} \mathrm{PO}_{4}$ (Carlo Erba), $\mathrm{NaOH}$ (Merck), and all other chemicals were purchased from Sigma Chemical Co. (USA). All solutions used in the experiments were prepared immediately before their use. Epinephrine solutions were prepared with phosphate buffer solution aerated with oxygen gas for $10 \mathrm{~min}$.

2.1.2. Apparatus. In the experiments Metrohm Autolab Type 3, potentiostat, Nova 1.9 software, a three-electrode system: carbon paste (glass tube, $5 \mathrm{~cm}$ length and $4 \mathrm{~mm}$ diameter) as a working electrode, $\mathrm{Ag} / \mathrm{AgCl}$ as a reference electrode, and a platinum wire as a counterelectrode, Gilson P100 and P1000 automatic pipettes (France), and Yellow-Line magnetic stirrer (Germany) were used. USF ELGA UHQ water purification system was used for high purity water $\left(18 \mathrm{M} \Omega \mathrm{cm}^{-1}\right)$.

2.2. Preparation of Carbon Paste Electrode. Modified carbon paste electrodes (CP/MWCNT/Tyr/Nafion) were prepared by mixing the appropriate ratios of graphite powder, MWCNT, and mineral oil. For this purpose, $0.69 \mathrm{~g}$ of graphite powder, $0.01 \mathrm{~g}$ of MWCNT, and $0.3 \mathrm{~g}$ of mineral oil were weighed and mixed on a glass plate until a homogeneous paste was observed. Then this mixture was placed into the cylindrical glass tube (i.d. $\approx 4 \mathrm{~mm}$ ) and packed down firmly using a rod. Electrical contact for the electrode was established via copper wire. After that, $10 \mu \mathrm{L}$ of Tyr solution was dropped onto the carbon paste electrode surface. Finally, $5 \mu \mathrm{L}$ of Nafion solution was added onto the electrode surface and then dried for $90 \mathrm{~min}$ before use. Unmodified carbon paste electrodes (CP/Nafion) were also prepared by the same procedure but mixing only $0.7 \mathrm{~g}$ of graphite powder and $0.3 \mathrm{~g}$ of mineral oil.

2.3. Electrochemical Measurement. Electrochemical measurements were performed with cyclic and differential pulse voltammetry in a voltammetric cell. Before each voltammetric measurement background currents were obtained in 


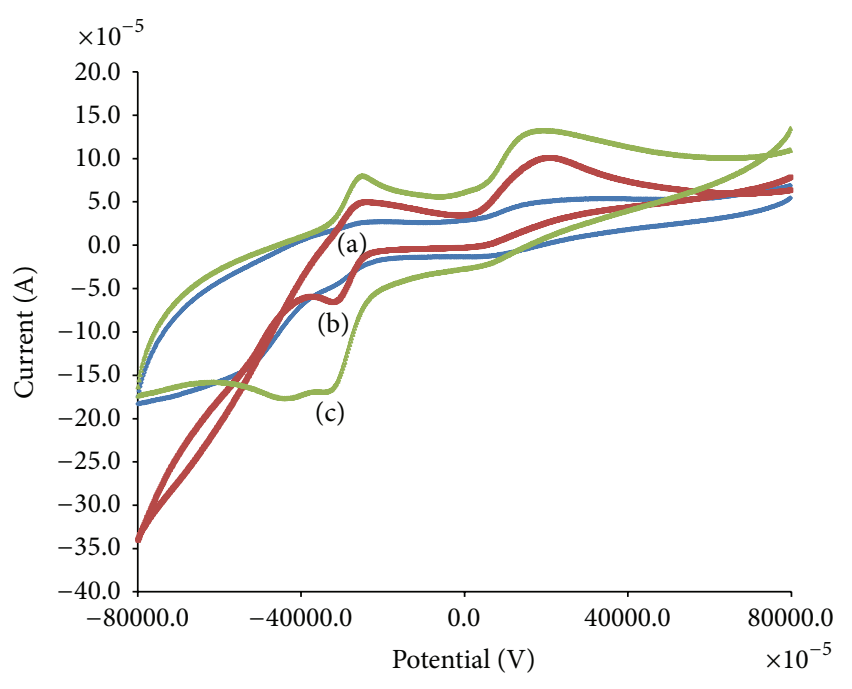

FIGURE 1: Cyclic voltammograms of the unmodified and modified biosensors: (a) CP/Nafion electrode; (b) CP/MWCNT/Nafion; and (c) CP/MWCNT/Tyr/Nafion in $50 \mathrm{mM}$ phosphate buffer, $\mathrm{pH} 7.0$ (T: $25^{\circ} \mathrm{C}$; Tyr: $313.087 \mathrm{U} / \mathrm{mL}$; scan rate: $50 \mathrm{mV} / \mathrm{s}$; EP: $1.0 \times 10^{-3} \mathrm{M}$; MWCNT: $1 \%(w / w)$; and Nafion: $5 \mu \mathrm{L})$.

$50 \mathrm{mM}$ pH 7.0 phosphate buffer solutions. Electrochemical determination of EP was established by addition of known concentration of EP solutions in voltammetric cell containing buffer solution. Solutions were stirred in voltammetric cell for $3 \mathrm{~min}$ before voltammetric measurement. Cyclic voltammograms (CVs) were recorded between $+0.8 \mathrm{~V}$ and $-0.8 \mathrm{~V}$. Differential pulse voltammograms (DPVs) were recorded in the cathodic direction between $+0.6 \mathrm{~V}$ and $-0.6 \mathrm{~V}$ under optimum experimental conditions.

2.4. Preparation of Pharmacological Sample. A pharmaceutical adrenalin ampoule containing $8.38 \mathrm{mg}$ sodium chloride, $0.1 \mathrm{mg}$ sodium metabisulphite, $1 \mathrm{~mL}$ injection water, and $1 \mathrm{mg}$ adrenalin was used in experiments. Before the voltammetric measurements, adrenalin ampoule was diluted in a voltammetric cell containing $1.0 \times 10^{-4} \mathrm{M}$ EP. DPVs of pharmacological sample were recorded in the cathodic direction between $+0.6 \mathrm{~V}$ and $-0.6 \mathrm{~V}$ under optimum experimental conditions. EP content of the diluted adrenalin ampoule was directly analysed by DPV without using any further pretreatment. Analyses were performed with two different commercial adrenalin ampoules with the same content.

\section{Results and Discussion}

3.1. Electrochemical Behaviour of Biosensor. Cyclic voltammograms of unmodified and modified carbon paste electrodes for epinephrine were recorded between $+0.8 \mathrm{~V}$ and $-0.8 \mathrm{~V}$ (Figure 1) in phosphate buffer solution. Compared with the $\mathrm{CP} / \mathrm{Nafion}$ electrode, the peak current of EP increased with $\mathrm{CP} / \mathrm{MWCNT} /$ Nafion electrode. While the cathodic peak of CP/Nafion electrode was observed at $-0.30 \mathrm{~V}$ as $2.3 \mu \mathrm{A}$, the cathodic peak of CP/MWCNT/Nafion electrode was obtained at $-0.31 \mathrm{~V}$ as $29.7 \mu \mathrm{A}$ for $1.0 \times 10^{-3} \mathrm{M}$ of EP. Furthermore, peak current significantly increased

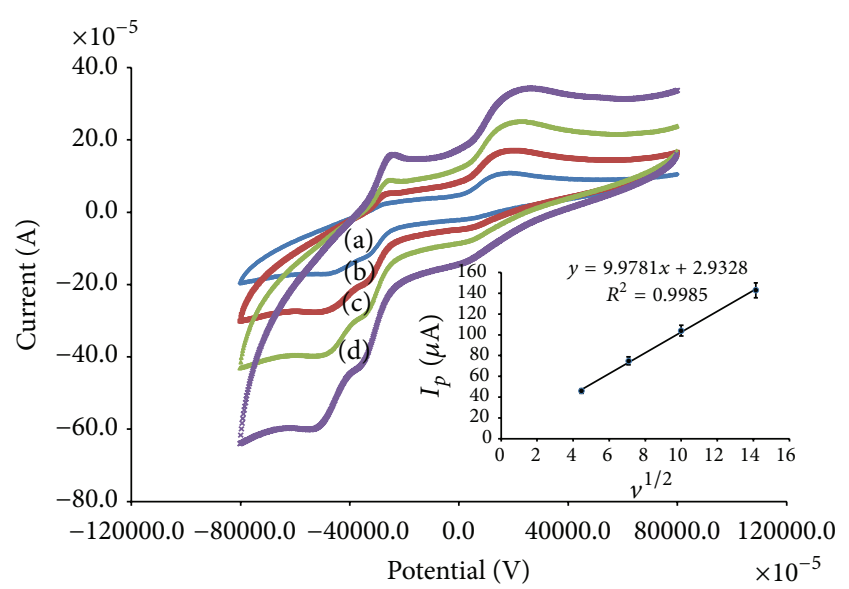

Figure 2: Cyclic voltammograms of the CP/MWCNT/Tyr/Nafion biosensor at different scan rates in $50 \mathrm{mM}$ phosphate buffer, $\mathrm{pH}$ 7.0. (a) $20 \mathrm{mV} / \mathrm{s}$; (b) $50 \mathrm{mV} / \mathrm{s}$; (c) $100 \mathrm{mV} / \mathrm{s}$; and (d) $200 \mathrm{mV} / \mathrm{s}$. Inset shows the plot of $I_{p}$ versus $v^{1 / 2}$ (Tyr: $313.087 \mathrm{U} / \mathrm{mL}$; EP: $1.0 \times 10^{-4} \mathrm{M}$; MWCNT: $1 \%(\mathrm{w} / \mathrm{w})$; and Nafion: $5 \mu \mathrm{L})$.

with CP/MWCNT/Tyr/Nafion electrode. Peak potential slightly shifted to the cathodic direction and peak was observed at $-0.33 \mathrm{~V}$ as $85.4 \mu \mathrm{A}$. These results can be attributed to the electrocatalytic effect of MWCNT which has an important role in electron transfer reaction and reducing electroactive species of o-quinone after producing a reaction between the Tyr enzyme and EP on the electrode surface.

3.2. Effect of Scan Rate. The effect of scan rate on biosensor response was investigated for $1.0 \times 10^{-4} \mathrm{M} \mathrm{EP}$ at different scan rates (Figure 2). Cyclic voltammograms show the differences between electrode responses depending on scan rates. A linear graph with a good correlation factor $\left(R^{2}=0.9985\right)$ was obtained for peak current versus square root of scan rate $\left(I_{p}-v^{1 / 2}\right)$ in the scan rate range $20 \mathrm{mV} / \mathrm{s}$ to $200 \mathrm{mV} / \mathrm{s}$. It was shown that the diffusion-controlled mechanism occurred for the enzymatic reaction.

3.3. Optimization of Amount of MWCNT. The effect of the amount of MWCNT on the CP/MWCNT/Tyr/Nafion electrode response was investigated with various increasing amounts of MWCNT ranging from $0.5 \%(\mathrm{w} / \mathrm{w})$ to $10 \%$ $(\mathrm{w} / \mathrm{w})$ in carbon paste by using differential pulse voltammetry towards cathodic direction (Figure 3). Increasing the amount of MWCNT caused a decrease of peak current. The large surface area of MWCNT is an advantage for the modification process preparing the biosensor but it can cause the increase of background current. Therefore, the decrease of peak current can be attributed to the increase of background current. Similar findings were also reported in previous works $[44,45]$. Therefore, the maximum peak current was obtained with $1 \%(w / w)$ of MWCNT amount for $1.0 \times 10^{-4} \mathrm{M}$ of EP saturated with oxygen at $\mathrm{pH}$ 7.0.

3.4. The Effect of Tyr Enzyme Activity on Biosensor Response. The optimization of Tyr enzyme activity was established 


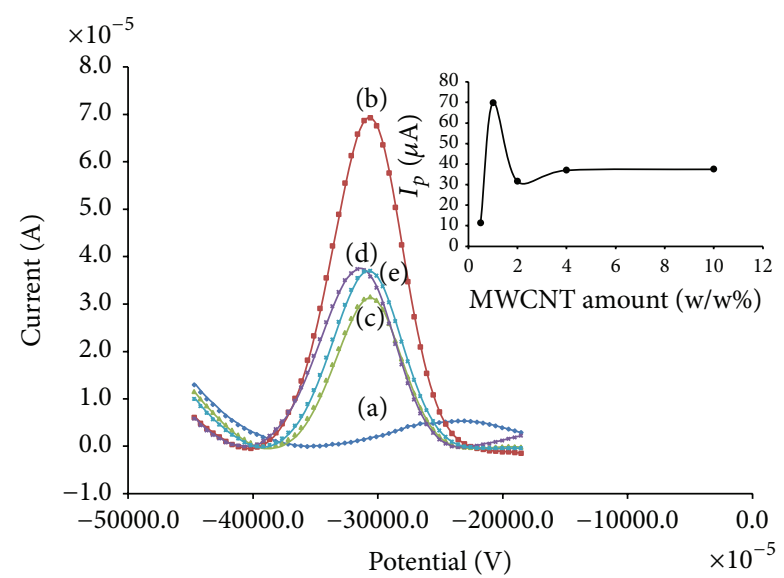

FIgURE 3: Differential pulse voltammograms of the CP/MWCNT/ Tyr/Nafion biosensor at different MWCNT amounts in $50 \mathrm{mM}$ phosphate buffer, pH 7.0. (a) $0.5 \%(\mathrm{w} / \mathrm{w})$; (b) $1 \%(\mathrm{w} / \mathrm{w})$; (c) $2 \%(\mathrm{w} / \mathrm{w})$; (d) $4 \%(\mathrm{w} / \mathrm{w})$; and (e) $10 \%(\mathrm{w} / \mathrm{w})$. Inset: plot of $I_{p}$ versus $\%$ MWCNT amounts (Tyr: $313.087 \mathrm{U} / \mathrm{mL}$; EP: $1.0 \times 10^{-4} \mathrm{M}$; scan rate: $50 \mathrm{mV} / \mathrm{s}$; and Nafion: $5 \mu \mathrm{L})$.

with various enzyme activities for different concentration of epinephrine solutions. For this aim, $156.540 \mathrm{U} / \mathrm{mL}$, $313.087 \mathrm{U} / \mathrm{mL}$, and $626.174 \mathrm{U} / \mathrm{mL}$ enzyme activities were chosen. Differential pulse voltammograms of CP/MWCNT/ Tyr/Nafion electrode were obtained towards cathodic direction $0.6 \mathrm{~V}$ to $-0.6 \mathrm{~V}$ with $50 \mathrm{mV} / \mathrm{s}$ scan rate. Biosensor responses were recorded for $1.0 \times 10^{-5} \mathrm{M}, 5.0 \times 10^{-5} \mathrm{M}$, $1.0 \times 10^{-4} \mathrm{M}$, and $2.0 \times 10^{-4} \mathrm{MEP}$ solutions with these enzyme activities. The peaks belonging to the reduction of EP were obtained at $-0.32 \mathrm{~V}$ for both enzyme activities of $313.087 \mathrm{U} / \mathrm{mL}$ and $626.174 \mathrm{U} / \mathrm{mL}$.

The linear graphs of peak current versus different concentrations of EP solutions for chosen enzyme activities show the enzyme activity effect on the biosensor response (Figure 4). The best correlation coefficient was obtained with $313.087 \mathrm{U} / \mathrm{mL}$ of Tyr activity as 0.9946 and this was used for further experiments.

3.5. The Effect of pH on Biosensor Response. Due to its importance, the effect of $\mathrm{pH}$ on CP/MWCNT/Tyr/Nafion electrode response was also investigated by using differential pulse voltammetry. $50 \mathrm{mM}$ phosphate buffer solutions were prepared at different $\mathrm{pH}$ values between 5.0 and 9.0 and differential pulse voltammograms were recorded for each $\mathrm{pH}$ value at $1.0 \times 10^{-4} \mathrm{MEP}$ of concentration. The graph of peak current versus $\mathrm{pH}$ values shows that the peak current increased from $\mathrm{pH} 5.0$ to $\mathrm{pH} 7.0$ (Figure 5). At $\mathrm{pH} 8.0$, very low peak current was obtained and at $\mathrm{pH} 9.0$ no peak was observed. Associated with increasing $\mathrm{pH}$ value, the biosensor displays more reaction at low $\mathrm{pH}$ range. This increase could be connected with the intensified tyrosinase activity parallel to the elevated $\mathrm{pH}$. At $\mathrm{pH}$ levels above 7.0, the amperometric reaction decreases subject to the contribution of protons to the hydroxylation of phenol catalyzed by the enzyme to form o-diphenol and to the reduction of o-quinone [46]. The optimum $\mathrm{pH}$ range is reported as range of $5-8$ for optimum

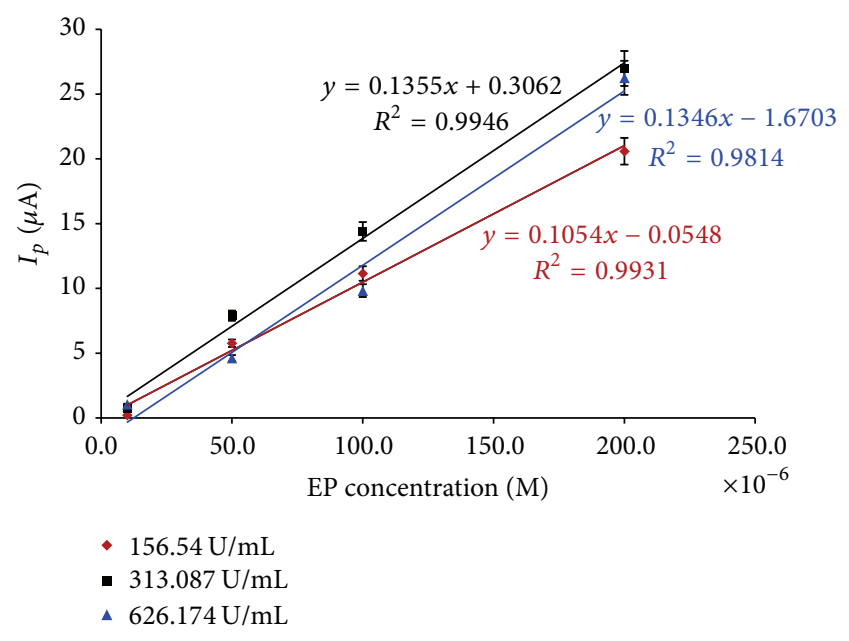

FIgURE 4: Plot of $I_{p}$ versus EP concentration at different enzyme activities $156.540 \mathrm{U} / \mathrm{mL}$ (red diamond); 313.087 U/mL (black square); and $626.174 \mathrm{U} / \mathrm{mL}$ (blue triangle) (electrode: $\mathrm{CP} / \mathrm{MWCNT}$ / Tyr/Nafion biosensor; MWCNT: 1\% (w/w); supporting electrolyte: $50 \mathrm{mM}$ phosphate buffer, $\mathrm{pH}$ 7.0; scan rate: $50 \mathrm{mV} / \mathrm{s}$; Nafion: $5 \mu \mathrm{L}$; and EP concentration range: $1.0 \times 10^{-5} \mathrm{M}$ to $2.0 \times 10^{-4} \mathrm{M}$ ).

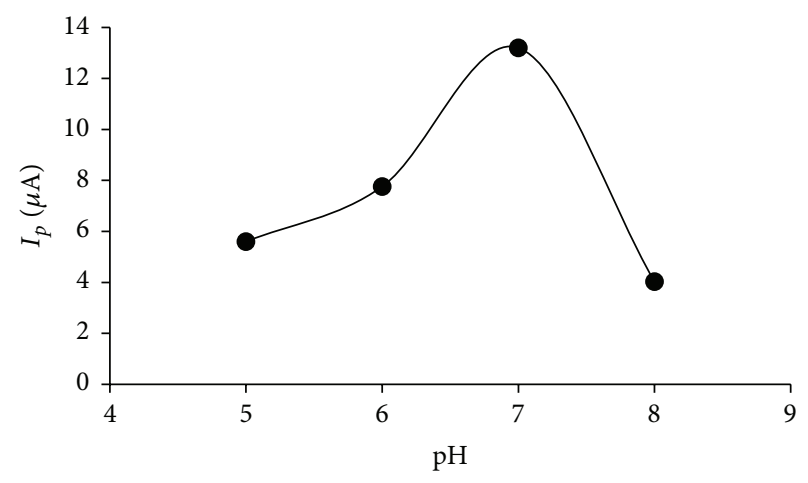

FIgURE 5: Plot of $I_{p}$ versus pH values. (a) 5.0; (b) 6.0; (c) 7.0; and (d) 8.0 (electrode: CP/MWCNT/Tyr/Nafion biosensor; MWCNT: $1 \%$ (w/w); supporting electrolyte: $50 \mathrm{mM}$ phosphate buffer, $\mathrm{pH}$ 7.0; scan rate: $50 \mathrm{mV} / \mathrm{s}$; Nafion: $5 \mu \mathrm{L}$; Tyr: $313.087 \mathrm{U} / \mathrm{mL}$; and $\mathrm{EP}: 1.0 \times 10^{-4} \mathrm{M}$ ).

free tyrosinase [47]. In order to have the best biosensor reaction, the optimum $\mathrm{pH}$ values were determined as 7.0, 7.4 , or $7.5[43,46,47]$. The relevant literature results support the immobilization procedure of the biosensor which does not display impact on the tyrosinase activity. Therefore, the optimum value under working experimental conditions was found to be $\mathrm{pH}$ 7.0.

3.6. Interference Effects. Ascorbic acid (AA) and uric acid (UA) found in real samples cause an interference effect on the determination of EP with a biosensor. This effect can be prevented by coating the biosensor surface with a suitable membrane. To remove AA and UA from the biosensor surface, the $\mathrm{CP} / \mathrm{MWCNT} / \mathrm{Tyr}$ surface was coated with a Nafion membrane. At pH 7.0, the negatively charged region of Nafion due to its fluoride ions prevents positively charged ions like $\mathrm{AA}$ and UA from reaching the biosensor surface. 


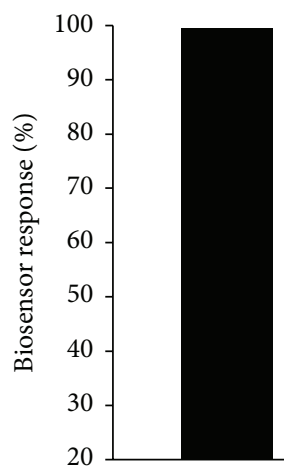

(a)

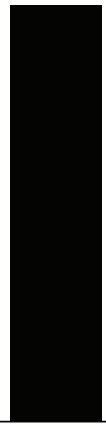

(b)

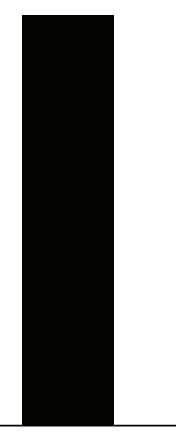

(c)
Figure 6: Interference effect on the CP/MWCNT/Tyr/Nafion biosensor response. Differential pulse voltammograms were recorded at (a) presence of $1.0 \times 10^{-4} \mathrm{MEP}$; (b) $1.0 \times 10^{-4} \mathrm{MEP}$ and equal concentration of $\mathrm{AA}$; and (c) $1.0 \times 10^{-4} \mathrm{MEP}$ and equal concentration of UA (Tyr: $313.087 \mathrm{U} / \mathrm{mL}$; PBS pH: 7.0, $50 \mathrm{mM}$; scan rate: $50 \mathrm{mV} / \mathrm{s}$; and Nafion: $5 \mu \mathrm{L}$ ).

The interference effects of AA and UA were examined with a solution containing $1.0 \times 10^{-4} \mathrm{MEP}$ and an equal concentration of interfering ion. The peak current value of biosensor for the EP solution only was accepted as 100\% and biosensor response when adding the interfering ion was evaluated relatively considering this value. Peak current value was found to be $97.0 \%$ with a solution containing $1.0 \times 10^{-4} \mathrm{M} \mathrm{EP}$ and an equal concentration of interfering ion. The peak current value of biosensor for the EP solution only was accepted as $100 \%$ and biosensor response when adding the interfering ion was evaluated relatively considering this value. Peak current value was found to be $97.0 \%$ with a solution containing $1.0 \times$ $10^{-4} \mathrm{MEP}$ and $1.0 \times 10^{-4} \mathrm{M}$ AA. When also studied with a solution containing $1.0 \times 10^{-4} \mathrm{M} \mathrm{EP}$ and $1.0 \times 10^{-4} \mathrm{M} \mathrm{UA}$, peak current value was found to be $96.0 \%$ (Figure 6). These results showed that the $\mathrm{CP} / \mathrm{MWCNT} / \mathrm{Tyr} / \mathrm{Nafion}$ biosensor can be used for voltammetric determination of EP for natural samples containing AA and UA.

3.7. Storage Stability of Biosensor. To examine storage stability, differential pulse voltammograms of CP/MWCNT/ Tyr/Nafion biosensor for $1.0 \times 10^{-4} \mathrm{M}$ EP solution at optimum experimental conditions were recorded every 2 days for a period of 15 days. The biosensor was stored in a refrigerator at $+4^{\circ} \mathrm{C}$ when not used. Figure 7 shows the changes of storage stability of the biosensor over 15 days. The biosensor response value at first day was accepted as $100 \%$. After 15 days, the biosensor activity remained at $70 \%$.

\subsection{Analytical Characteristics of the CP/MWCNT/Tyr/Nafion Biosensor}

3.8.1. Linear Range of the CP/MWCNT/Tyr/Nafion Biosensor. To determine a linear range of the CP/MWCNT/Tyr/Nafion biosensor, differential pulse voltammograms for different concentration of EP were examined (Figure 8). The biosensor showed a linear response between $5.0 \times 10^{-6} \mathrm{M}$ and $5.0 \times$ $10^{-4}$ M EP concentration $(y=12.909 x+0.5142)$ with a good

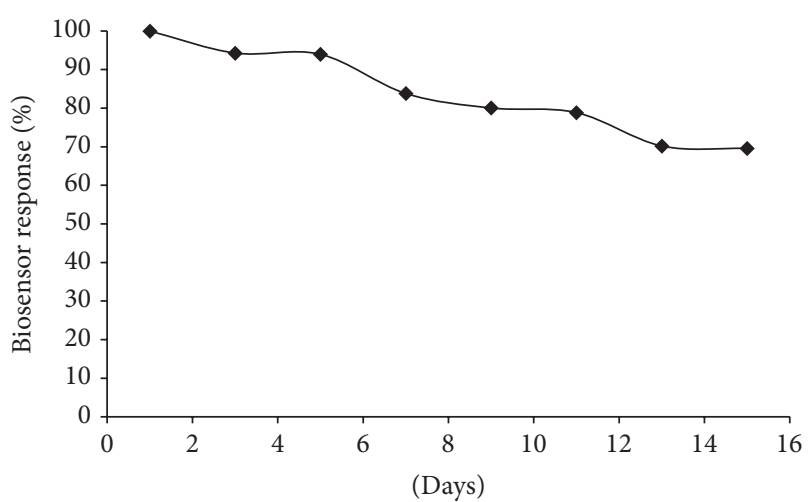

FIgURE 7: Storage stability graphic (Tyr: $313.087 \mathrm{U} / \mathrm{mL}$; EP: $1.0 \times$ $10^{-4} \mathrm{M}$; PBS pH: 7.0, $50 \mathrm{mM}$; scan rate: $50 \mathrm{mV} / \mathrm{s}$; and Nafion: $5 \mu \mathrm{L}$ ).

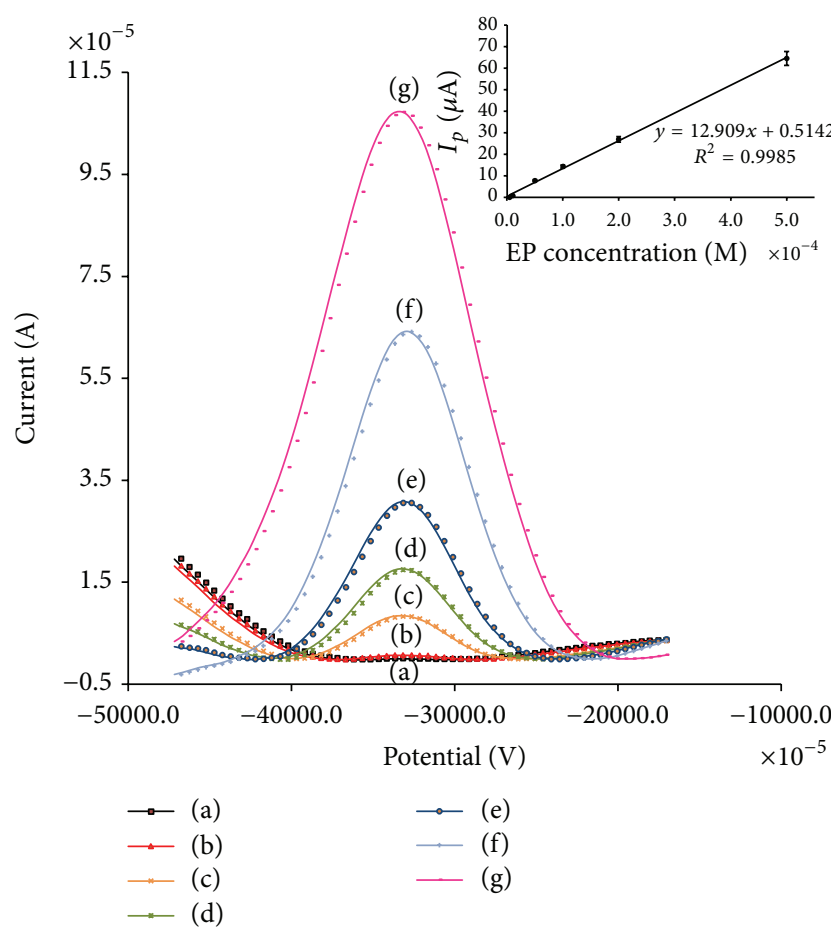

FIGURE 8: Differential pulse voltammograms of the CP/MWCNT/ Tyr/Nafion biosensor at different concentration of EP; (a) baseline, (b) $5.0 \times 10^{-6} \mathrm{M}$, (c) $1.0 \times 10^{-5} \mathrm{M}$, (d) $5.0 \times 10^{-5} \mathrm{M}$, (e) $1.0 \times 10^{-4} \mathrm{M}$, (f) $2.0 \times 10^{-4} \mathrm{M}$, and (g) $5.0 \times 10^{-4} \mathrm{M}$. Inset: plot of peak current as a function of EP concentration (Tyr: $313.087 \mathrm{U} / \mathrm{mL}$; supporting electrolyte: $50 \mathrm{mM}$ phosphate buffer, $\mathrm{pH} 7.0$; scan rate: $50 \mathrm{mV} / \mathrm{s}$; and Nafion: $5 \mu \mathrm{L}$; error bars indicate the standard deviations $n=3$ ).

correlation coefficient $\left(R^{2}=0.9985\right)$ (Figure 8$)$. The detection limit of the biosensor was calculated as $3.0 \times 10^{-7} \mathrm{M}$ EP from the signal-to-noise ratio $(\mathrm{S} / \mathrm{N}=3)$.

A comparison of the analytical performance of the biosensor with other electrodes was given in Table 1. According to Table 1 , the developed biosensor shows wider linear range than some of them $[3,4,21,27,30,32-35,48,49$, 51]. The detection limit of the developed biosensor is also better than some electrodes $[27,30,32,33,35,48,49,51$, 


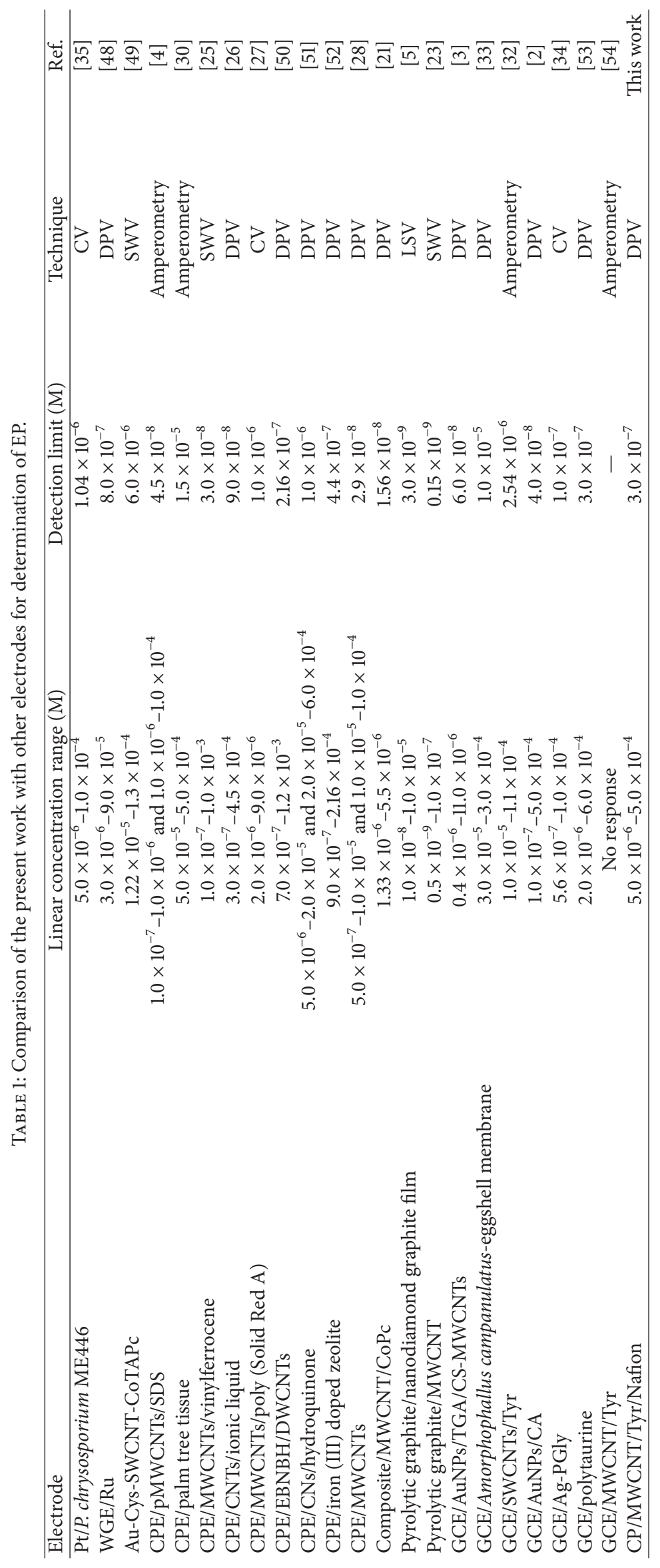


TABLE 2: Determination of EP in adrenalin ampoule.

\begin{tabular}{lccc}
\hline Sample & EP content $(\mathrm{M})$ & EP found $(\mathrm{M})$ & ${ }^{*}$ RSD\% \\
\hline Ampoule 1 & $1.0 \times 10^{-4}$ & $9.73 \times 10^{-5}$ & 4.62 \\
Ampoule 2 & $1.0 \times 10^{-4}$ & $9.80 \times 10^{-5}$ & 4.38 \\
\hline
\end{tabular}

${ }^{*}$ Relative standard deviation for three replicates' measurements.

53]. When studies in which modified carbon paste electrode and differential pulse methods are used to estimate the EP are taken into consideration, their estimation limits were determined as $9.0 \times 10^{-8} \mathrm{M}$ for $\mathrm{CPE} / \mathrm{CNTs} /$ ionic liquid [26], $2.16 \times 10^{-7} \mathrm{M}$ for CPE/EBNBH/DWCNTs [50], $1.0 \times 10^{-6} \mathrm{M}$ for $\mathrm{CPE} / \mathrm{CNs}$ /hydroquinone [51], $4.4 \times 10^{-7} \mathrm{M}$ for $\mathrm{CPE} /$ iron (III) doped zeolite [52], and $2.9 \times 10^{-8} \mathrm{M}$ for CPE/MWCNTs [28]. In the present study, obtained estimation limit value is comparable with the findings reported in the relevant literature.

3.8.2. Reproducibility of the CP/MWCNT/Tyr/Nafion Biosensor. The reproducibility of the developed biosensor was also investigated. Electrode-to-electrode reproducibility was examined by preparation of five biosensors in the same conditions. These experiments were realized under optimum experimental conditions for $1.0 \times 10^{-4} \mathrm{MEP}$. From the data obtained the relative standard deviation (RSD\%) was calculated as $3.8 \%$.

3.9. Pharmacological Sample Analysis. To prove the applicability of the developed biosensor to EP determination, a pharmaceutical adrenalin ampoule was used. Voltammetric analysis of diluted ampoule solution was directly performed without using any further pretreatment. Approximate plasma value of the $\mathrm{EP}$ was determined as $3.0 \pm 3.0 \mathrm{ng} / 100 \mathrm{~mL}$ [6]. It is not possible to estimate the EP value in plasma by means of the introduced CP/MWCNT/Tyr/Nafion biosensor. However, it could be possible to make this estimation through standard addition method. In the available studies in the literature, pharmacological examples were usually utilized $[26,28,50-52]$. For the plasma sample, the EP level was estimated through the standard addition method in the form of recovery $[26,28,50,52]$.

The results show that the CP/MWCNT/Tyr/Nafion biosensor has good reproducibility for the pharmacological sample analysis (Table 2). Consequently, the proposed biosensor can be used for determining EP in a pharmacological sample with high accuracy and precision and simple operation.

\section{Conclusions}

In the present study, a carbon paste electrode modified with MWCNT, Tyr, and Nafion was used for the determination of EP. The CP/MWCNT/Tyr/Nafion biosensor was successfully applied for the voltammetric determination of EP in the presence of AA and UA and also in a pharmaceutical sample. The results show that the biosensor, prepared combining the unique electronic effect of MWCNT and catalytic effect of Tyr enzyme, has a wide linear range and low detection limit. The developed CP/MWCNT/Tyr/Nafion biosensor has the potential to be used for detection of EP because of its simple preparation technique, its cheapness, the lack of extra purification steps required, and a rapid and easy operation.

\section{Competing Interests}

The authors declare that there is no conflict of interests regarding the publication of this paper.

\section{References}

[1] J.-A. Ni, H.-X. Ju, H.-Y. Chen, and D. Leech, "Amperometric determination of epinephrine with an osmium complex and Nafion double-layer membrane modified electrode," Analytica Chimica Acta, vol. 378, no. 1-3, pp. 151-157, 1999.

[2] Z. Yang, G. Hu, X. Chen, J. Zhao, and G. Zhao, "The nano-Au self-assembled glassy carbon electrode for selective determination of epinephrine in the presence of ascorbic acid," Colloids and Surfaces B: Biointerfaces, vol. 54, no. 2, pp. 230-235, 2007.

[3] P. S. Dorraji and F. Jalali, "Novel sensitive electrochemical sensor for simultaneous determination of epinephrine and uric acid by using a nanocomposite of MWCNTs-chitosan and gold nanoparticles attached to thioglycolic acid," Sensors and Actuators B: Chemical, vol. 200, pp. 251-258, 2014.

[4] T. Thomas, R. J. Mascarenhas, O. J. D'Souza, S. Detriche, Z. Mekhalif, and P. Martis, "Pristine multi-walled carbon nanotubes/SDS modified carbon paste electrode as an amperometric sensor for epinephrine," Talanta, vol. 125, pp. 352-360, 2014.

[5] S. Shahrokhian and M. Khafaji, "Application of pyrolytic graphite modified with nano-diamond/graphite film for simultaneous voltammetric determination of epinephrine and uric acid in the presence of ascorbic acid," Electrochimica Acta, vol. 55, no. 28, pp. 9090-9096, 2010.

[6] P. Coulombe, J. H. Dussault, J. Letarte, and S. J. Simard, "Catecholamines metabolism in thyroid diseases. I. Epinephrine secretion rate in hyperthyroidism and hypothyroidism," The Journal of Clinical Endocrinology \& Metabolism, vol. 42, no. 1, pp. 125-131, 1976.

[7] P. Solich, Ch. K. Polydorou, M. A. Koupparis, and C. E. Efstathiou, "Automated flow-injection spectrophotometric determination of catecholamines (epinephrine and isoproterenol) in pharmaceutical formulations based on ferrous complex formation," Journal of Pharmaceutical and Biomedical Analysis, vol. 22, no. 5, pp. 781-789, 2000.

[8] M. H. Sorouraddin, J. L. Manzoori, E. Kargarzadeh, and A. M. H. Shabani, "Spectrophotometric determination of some catecholamine drugs using sodium bismuthate," Journal of Pharmaceutical and Biomedical Analysis, vol. 18, no. 4-5, pp. 877-881, 1998.

[9] V. Carrera, E. Sabater, E. Vilanova, and M. A. Sogorb, "A simple and rapid HPLC-MS method for the simultaneous determination of epinephrine, norepinephrine, dopamine and 5-hydroxytryptamine: application to the secretion of bovine chromaffin cell cultures," Journal of Chromatography B: Analytical Technologies in the Biomedical and Life Sciences, vol. 847, no. 2, pp. 88-94, 2007.

[10] M. A. Fotopoulou and P. C. Ioannou, "Post-column terbium complexation and sensitized fluorescence detection for the determination of norepinephrine, epinephrine and dopamine 
using high-performance liquid chromatography," Analytica Chimica Acta, vol. 462, no. 2, pp. 179-185, 2002.

[11] X. Zheng, Z. Guo, and Z. Zhang, "Flow-injection electrogenerated chemiluminescence determination of epinephrine using luminol," Analytica Chimica Acta, vol. 441, no. 1, pp. 81-86, 2001.

[12] J. Du, L. Shen, and J. Lu, "Flow injection chemiluminescence determination of epinephrine using epinephrine-imprinted polymer as recognition material," Analytica Chimica Acta, vol. 489, no. 2, pp. 183-189, 2003.

[13] J. Michałowski and P. Hałaburda, "Flow-injection chemiluminescence determination of epinephrine in pharmaceutical preparations using raw apple juice as enzyme source," Talanta, vol. 55, no. 6, pp. 1165-1171, 2001.

[14] S. Wei, G. Song, and J.-M. Lin, "Separation and determination of norepinephrine, epinephrine and isoprinaline enantiomers by capillary electrophoresis in pharmaceutical formulation and human serum," Journal of Chromatography A, vol. 1098, no. 1-2, pp. 166-171, 2005.

[15] Z. Lin, X. Wu, X. Lin, and Z. Xie, "End-column chemiluminescence detection for pressurized capillary electrochromatographic analysis of norepinephrine and epinephrine," Journal of Chromatography A, vol. 1170, no. 1-2, pp. 118-121, 2007.

[16] Y. Zhao, S. Zhao, J. Huang, and F. Ye, "Quantum dot-enhanced chemiluminescence detection for simultaneous determination of dopamine and epinephrine by capillary electrophoresis," Talanta, vol. 85, no. 5, pp. 2650-2654, 2011.

[17] W. K. Adeniyi and A. R. Wright, "Novel fluorimetric assay of trace analysis of epinephrine in human serum," Spectrochimica Acta Part A: Molecular and Biomolecular Spectroscopy, vol. 74, no. 5, pp. 1001-1004, 2009.

[18] J. Yang, G. Zhang, X. Wu et al., "Fluorimetric determination of epinephrine with o-phenylenediamine," Analytica Chimica Acta, vol. 363, no. 1, pp. 105-110, 1998.

[19] J. Yang, G. Zhang, X. Cao, L. Sun, and Y. Ding, "Fluorimetric determination of epinephrine with 2,3-diaminonaphthalene," Spectrochimica Acta A, vol. 53, no. 10, pp. 1671-1676, 1997.

[20] A. Babaei, M. Sohrabi, and M. Afrasiabi, "A sensitive simultaneous determination of epinephrine and piroxicam using a glassy carbon electrode modified with a nickel hydroxide nanoparticles/multiwalled carbon nanotubes composite," Electroanalysis, vol. 24, no. 12, pp. 2387-2394, 2012.

[21] F. C. Moraes, D. L. C. Golinelli, L. H. Mascaro, and S. A. S. MacHado, "Determination of epinephrine in urine using multiwalled carbon nanotube modified with cobalt phthalocyanine in a paraffin composite electrode," Sensors and Actuators B: Chemical, vol. 148, no. 2, pp. 492-497, 2010.

[22] X. Lu, Y. Li, J. Du et al., "A novel nanocomposites sensor for epinephrine detection in the presence of uric acids and ascorbic acids," Electrochimica Acta, vol. 56, no. 21, pp. 7261-7266, 2011.

[23] R. N. Goyal and S. Bishnoi, "Simultaneous determination of epinephrine and norepinephrine in human blood plasma and urine samples using nanotubes modified edge plane pyrolytic graphite electrode," Talanta, vol. 84, no. 1, pp. 78-83, 2011.

[24] R. N. Goyal and S. Bishnoi, "A novel multi-walled carbon nanotube modified sensor for the selective determination of epinephrine in smokers," Electrochimica Acta, vol. 56, no. 6, pp. 2717-2724, 2011.

[25] H. Beitollahi, M. A. Taher, and A. Hosseini, "Fabrication of a nanostructure-based electrochemical sensor for simultaneous determination of epinephrine and tryptophan," Measurement, vol. 51, no. 1, pp. 156-163, 2014.
[26] T. Tavana, M. A. Khalilzadeh, H. Karimi-Maleh, A. A. Ensafi, H. Beitollahi, and D. Zareyee, "Sensitive voltammetric determination of epinephrine in the presence of acetaminophen at a novel ionic liquid modified carbon nanotubes paste electrode," Journal of Molecular Liquids, vol. 168, pp. 69-74, 2012.

[27] J. G. Manjunatha, M. Deraman, N. H. Basri, and I. A. Talib, "Fabrication of poly (Solid Red A) modified carbon nano tube paste electrode and its application for simultaneous determination of epinephrine, uric acid and ascorbic acid," Arabian Journal of Chemistry, 2014.

[28] T. Thomas, R. J. Mascarenhas, P. Martis, Z. Mekhalif, and B. E. K. Swamy, "Multi-walled carbon nanotube modified carbon paste electrode as an electrochemical sensor for the determination of epinephrine in the presence of ascorbic acid and uric acid," Materials Science and Engineering C, vol. 33, no. 6, pp. 32943302, 2013.

[29] N. F. Atta, A. Galal, F. M. Abu-Attia, and S. M. Azab, "Simultaneous determination of paracetamol and neurotransmitters in biological fluids using a carbon paste sensor modified with gold nanoparticles," Journal of Materials Chemistry, vol. 21, no. 34, pp. 13015-13024, 2011.

[30] F. S. Felix, M. Yamashita, and L. Angnes, "Epinephrine quantification in pharmaceutical formulations utilizing plant tissue biosensors," Biosensors and Bioelectronics, vol. 21, no. 12, pp. 2283-2289, 2006.

[31] S. Shahrokhian and R.-S. Saberi, "Electrochemical preparation of over-oxidized polypyrrole/multi-walled carbon nanotube composite on glassy carbon electrode and its application in epinephrine determination," Electrochimica Acta, vol. 57, no. 1, pp. 132-138, 2011.

[32] I. M. Apetrei and C. Apetrei, "Biosensor based on tyrosinase immobilized on a single-walled carbon nanotube-modified glassy carbon electrode for detection of epinephrine," International Journal of Nanomedicine, vol. 8, no. 1, pp. 4391-4398, 2013.

[33] S. Tembe, S. Kulkarni, M. Karve, and S. F. D’Souza, "Epinephrine biosensor using tyrosinase immobilized eggshell membrane," Sensors \& Transducers Journal, vol. 107, no. 8, pp. 111-118, 2009.

[34] X. Li, M. Chen, and X. Ma, "Selective determination of epinephrine in the presence of ascorbic acid and dopamine at silver doped polyglycine modified electrode," International Journal of Electrochemical Science, vol. 7, no. 1, pp. 167-174, 2012.

[35] E. Akyilmaz, M. Turemis, and I. Yasa, "Voltammetric determination of epinephrine by White rot fungi (Phanerochaete chrysosporium ME446) cells based microbial biosensor," Biosensors and Bioelectronics, vol. 26, no. 5, pp. 2590-2594, 2011.

[36] F. A. De Souza Ribeiro, C. R. T. Tarley, K. B. Borges, and A. C. Pereira, "Development of a square wave voltammetric method for dopamine determination using a biosensor based on multiwall carbon nanotubes paste and crude extract of Cucurbita pepo L.," Sensors and Actuators B: Chemical, vol. 185, pp. 743-754, 2013.

[37] Y. Wang, W. Wei, X. Liu, and X. Zeng, "Carbon nanotube/chitosan/gold nanoparticles-based glucose biosensor prepared by a layer-by-layer technique," Materials Science and Engineering C, vol. 29, no. 1, pp. 50-54, 2009.

[38] B. J. Sanghavi and A. K. Srivastava, "Simultaneous voltammetric determination of acetaminophen, aspirin and caffeine using an in situ surfactant-modified multiwalled carbon nanotube paste electrode," Electrochimica Acta, vol. 55, no. 28, pp. 8638-8648, 2010.

[39] B. J. Sanghavi and A. K. Srivastava, "Adsorptive stripping differential pulse voltammetric determination of venlafaxine and 
desvenlafaxine employing Nafion-carbon nanotube composite glassy carbon electrode," Electrochimica Acta, vol. 56, no. 11, pp. 4188-4196, 2011.

[40] E. Asav, E. Yorganci, and E. Akyilmaz, "An inhibition type amperometric biosensor based on tyrosinase enzyme for fluoride determination," Talanta, vol. 78, no. 2, pp. 553-556, 2009.

[41] F. C. Vicentini, B. C. Janegitz, C. M. A. Brett, and O. FatibelloFilho, "Tyrosinase biosensor based on a glassy carbon electrode modified with multi-walled carbon nanotubes and 1-butyl-3methylimidazolium chloride within a dihexadecylphosphate film," Sensors and Actuators B: Chemical, vol. 188, pp. 1101-1108, 2013.

[42] H. Decker, R. Dillinger, and F. Tuczek, "How does tyrosinase work? Recent insights from model chemistry and structural biology," Angewandte Chemie-International Edition, vol. 39, no. 9, pp. 1591-1595, 2000.

[43] E. Canbay and E. Akyilmaz, "Design of a multiwalled carbon nanotube-Nafion-cysteamine modified tyrosinase biosensor and its adaptation of dopamine determination," Analytical Biochemistry, vol. 444, no. 1, pp. 8-15, 2014.

[44] Ü. Anık and M. Çubukçu, "Examination of the electroanalytic performance of carbon nanotube (CNT) modified carbon paste electrodes as xanthine biosensor transducers," Turkish Journal of Chemistry, vol. 32, no. 6, pp. 711-719, 2008.

[45] S. Timur, U. Anik, D. Odaci, and L. Gorton, "Development of a microbial biosensor based on carbon nanotube (CNT) modified electrodes," Electrochemistry Communications, vol. 9, no. 7, pp. 1810-1815, 2007.

[46] L. Chen, B. Gu, G. Zhu, Y. Wu, S. Liu, and C. Xu, "Electron transfer properties and electrocatalytic behavior of tyrosinase on $\mathrm{ZnO}$ nanorod," Journal of Electroanalytical Chemistry, vol. 617, no. 1, pp. 7-13, 2008.

[47] H. Yin, Y. Zhou, J. Xu, S. Ai, L. Cui, and L. Zhu, "Amperometric biosensor based on tyrosinase immobilized onto multiwalled carbon nanotubes-cobalt phthalocyanine-silk fibroin film and its application to determine bisphenol A," Analytica Chimica Acta, vol. 659, no. 1-2, pp. 144-150, 2010.

[48] G.-P. Jin, Q.-Z. Chen, Y.-F. Ding, and J.-B. He, "Electrochemistry behavior of adrenalin, serotonin and ascorbic acid at novel poly rutin modified paraffin-impregnated graphite electrode," Electrochimica Acta, vol. 52, no. 7, pp. 2535-2541, 2007.

[49] K. I. Ozoemena, D. Nkosi, and J. Pillay, "Influence of solution $\mathrm{pH}$ on the electron transport of the self-assembled nanoarrays of single-walled carbon nanotube-cobalt tetra-aminophthalocyanine on gold electrodes: electrocatalytic detection of epinephrine," Electrochimica Acta, vol. 53, no. 6, pp. 2844-2851, 2008.

[50] H. Beitollahi, M. M. Ardakani, B. Ganjipour, and H. Naeimi, "Novel 2,2I-[1,2-ethanediylbis(nitriloethylidyne)]-bishydroquinone double-wall carbon nanotube paste electrode for simultaneous determination of epinephrine, uric acid and folic acid," Biosensors and Bioelectronics, vol. 24, no. 3, pp. 362-368, 2008.

[51] M. Mazloum-Ardakani, N. Rajabzadeh, A. D. Firouzabadi et al., "Carbon nanoparticles and a new derivative of hydroquinone for modification of a carbon paste electrode for simultaneous determination of epinephrine and acetaminophen," Analytical Methods, vol. 4, no. 7, pp. 2127-2133, 2012.

[52] A. Babaei, S. Mirzakhani, and B. Khalilzadeh, "A sensitive simultaneous determination of epinephrine and tyrosine using an iron (III) doped zeolite-modified carbon paste electrode," Journal of the Brazilian Chemical Society, vol. 20, no. 10, pp. 1862-1869, 2009.
[53] Y. Wang and Z.-Z. Chen, "A novel poly(taurine) modified glassy carbon electrode for the simultaneous determination of epinephrine and dopamine," Colloids and Surfaces B: Biointerfaces, vol. 74, no. 1, pp. 322-327, 2009.

[54] Y.-C. Tsai and C.-C. Chiu, "Amperometric biosensors based on multiwalled carbon nanotube-Nafion-tyrosinase nanobiocomposites for the determination of phenolic compounds," Sensors and Actuators B: Chemical, vol. 125, no. 1, pp. 10-16, 2007. 


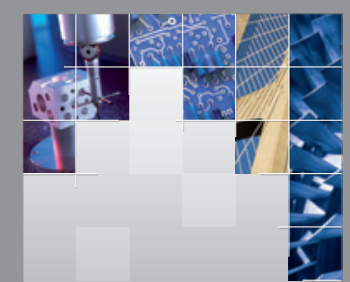

\section{Enfincering}
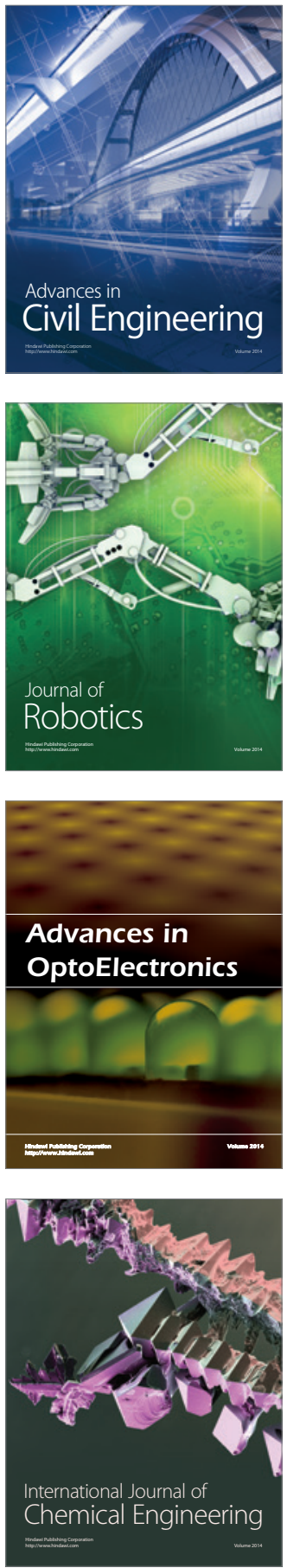

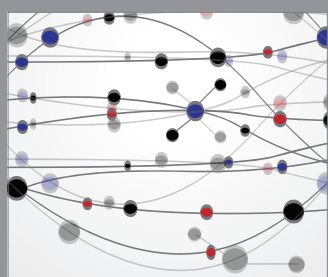

The Scientific World Journal

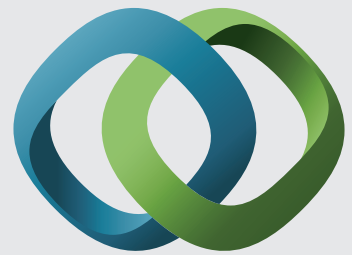

\section{Hindawi}

Submit your manuscripts at

http://www.hindawi.com
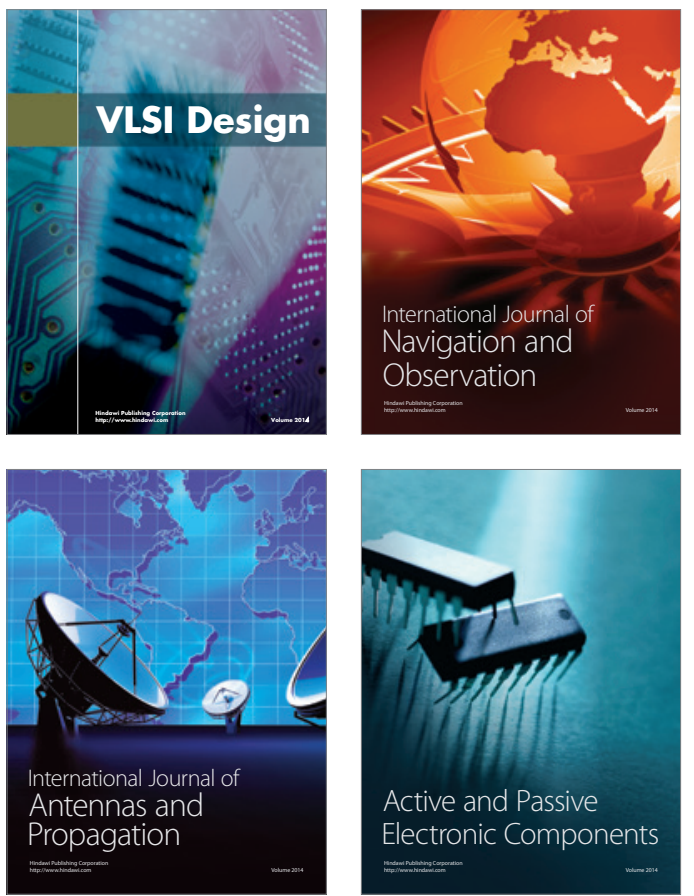
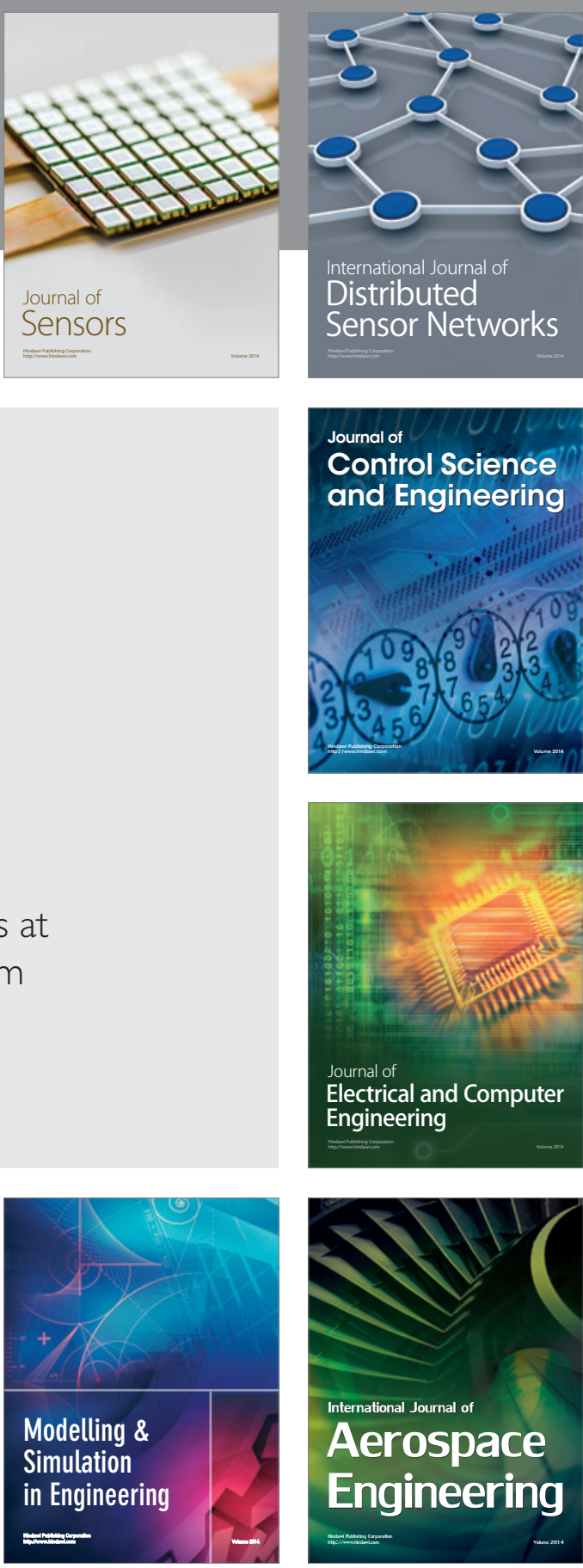

International Journal of

Distributed

Sensor Networks

Journal of

Control Science

and Engineering
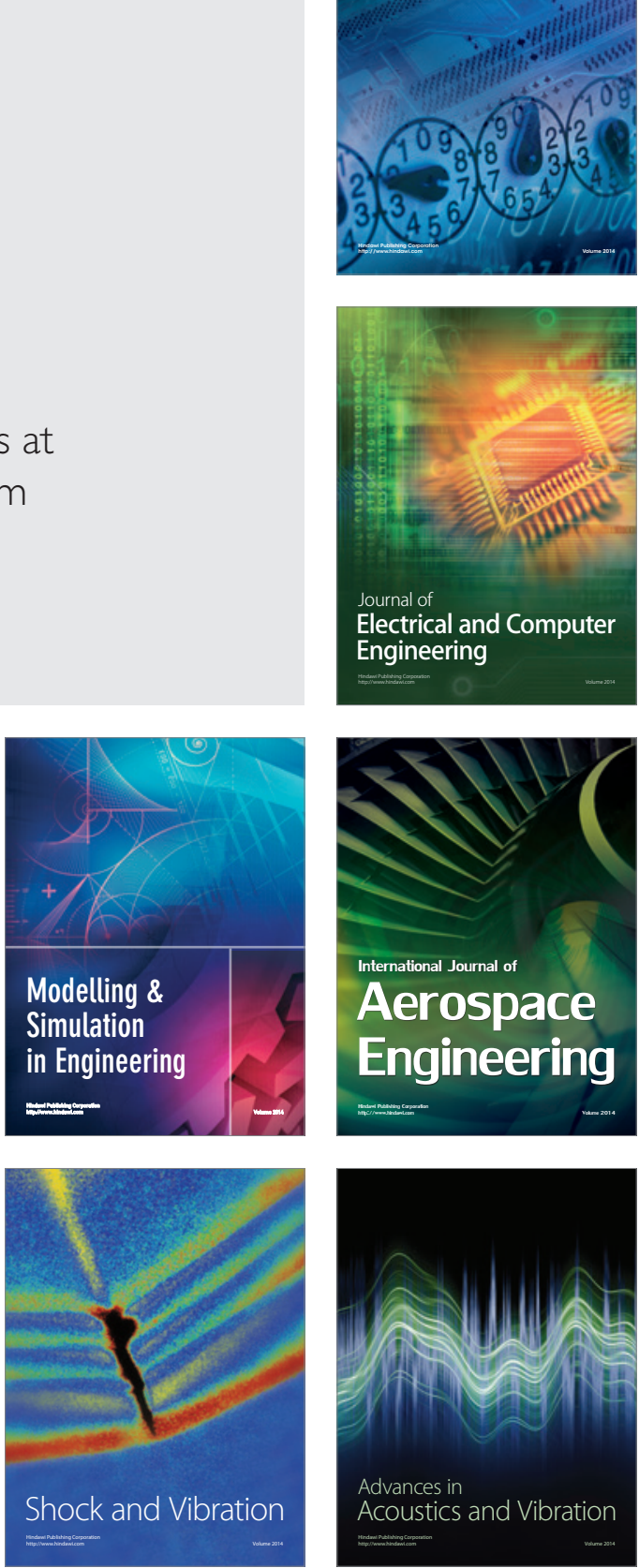